\title{
CORRIGENDUM
}

Genes \& Development 20: 2648-2653 (2006)

\section{Corrigendum: Hepatocytes with extensive telomere deprotection and fusion remain viable and regenerate liver mass through endoreduplication}

Eros Lazzerini Denchi, Giulia Celli, and Titia de Lange

In the original version of the above-mentioned article, the authors mistakenly used incorrectly labeled images for the immunohistochemistry panels in Figure 2C that were used to detect p53 and Caspase- 3 in liver sections of Mx-Cre $\mathrm{TRF}^{\mathrm{F} /-}$ mice either untreated or $6 \mathrm{~d}$ following pI-pC administration. The images presented for the p53 (P-Ser18) control mice (no pI-pC) and experimental mice (6 d post-pI-pC) and the images presented for activated Caspase-3 in control mice (no pI-pC) and experimental mice (6 d post-pI-pC) were derived from the same liver section, and it is unknown whether the images presented in the original Figure $2 \mathrm{C}$ were from control or experimental mice due to labelling errors. This mistake arose during figure preparation in 2005 and probably went unnoticed because none of the liver IHC images for p53 (P-Ser18) or activated Caspase-3 showed positive staining and were therefore difficult to distinguish. We were able to recover data from an earlier p53 (P-Ser18) staining experiment and these images were used to correct Figure 2C below.

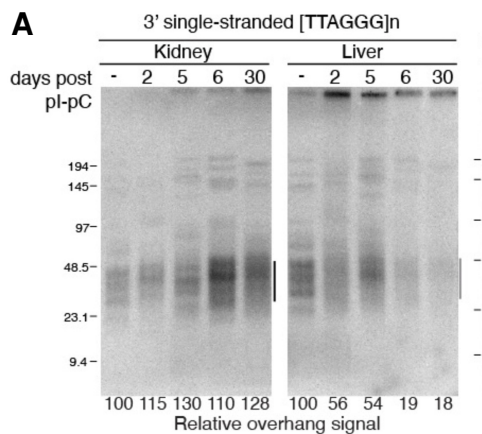

B

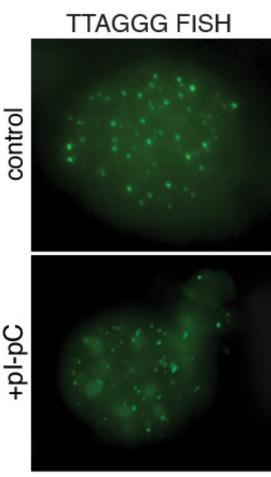

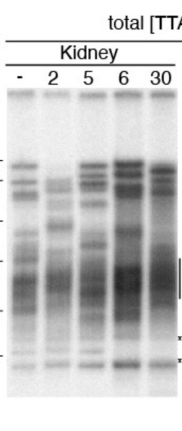
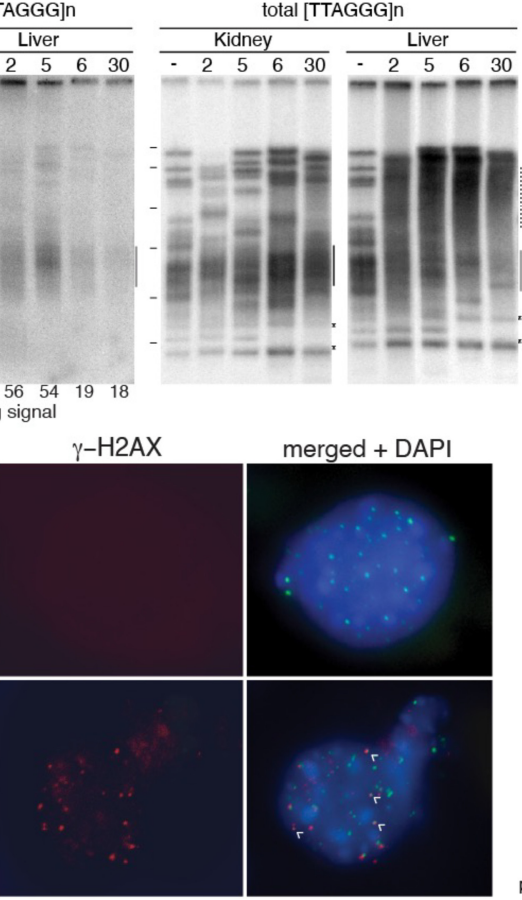

merged + DAPI

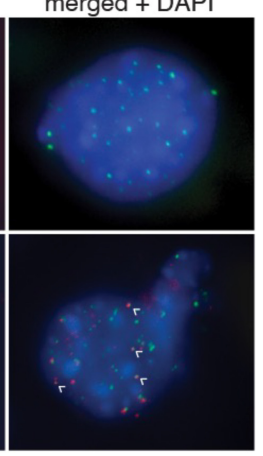

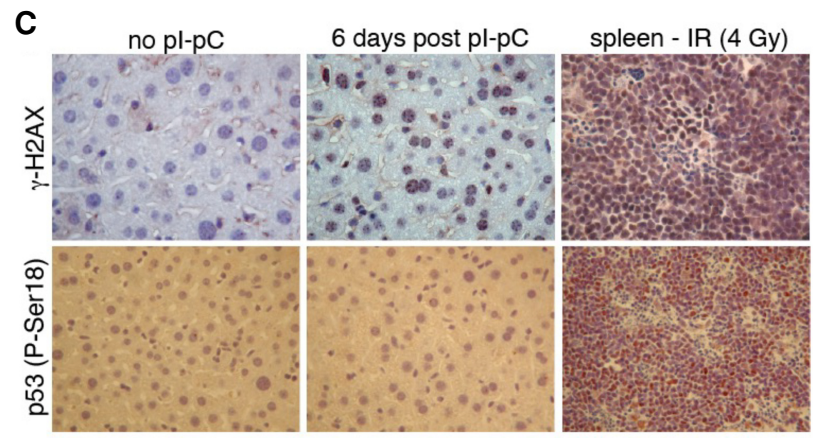

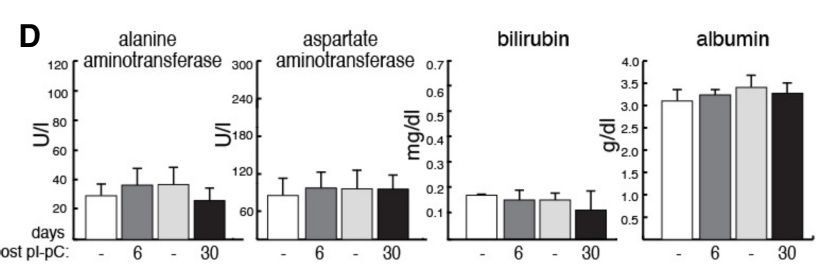

Figure 2. 
Please note that, unfortunately, our 2004/2005 electronic records of liver IHC for activated Caspase 3, while containing many negative images, were not appropriately labeled. Therefore, the Caspase- 3 data have not been replaced, as we cannot assign images as control and experimental representatives unequivocally. References to Caspase- 3 activation in the text in the following places should be omitted:

\begin{abstract}
The sentence "However, there was no induction of p53 or apoptosis, and liver function appeared unaffected." should now read "However, there was no induction of p53, and liver function appeared unaffected."
\end{abstract}

\title{
Results and Discussion
}

- On page 2649, column 2, the heading "Telomere dysfunction-induced foci (TIFs) but not p53 activation or apoptosis after telomere deprotection" should now read "Telomere dysfunction-induced foci (TIFs) but not p53 activation after telomere deprotection."

- On page 2650, column 1, paragraph 1, the sentence "Moreover, IHC for activated caspase 3 suggested that there was no prominent induction of apoptosis (Fig. 2C), and staining for SA- $\beta$-galactosidase failed to provide evidence for senescent cells (data not shown)." should now read "Moreover, staining for SA- $\beta$-galactosidase failed to provide evidence for senescent cells (data not shown)."

- On page 2650, column 1, paragraph 2, the sentence "Our finding that acute telomere deprotection in quiescent hepatocytes does not result in senescence or apoptosis contrasts with the results obtained with Adenoviral delivery of a dominant-negative allele of TRF2 (AdTRF2 $\left.{ }^{\triangle \mathrm{B} \Delta \mathrm{M}}\right)$..." should now read "Our finding that acute telomere deprotection in quiescent hepatocytes does not result in senescence contrasts with the results obtained with Adenoviral delivery of a dominant-negative allele of TRF2 $\left(\operatorname{AdTRF} 2^{\triangle \mathrm{B} \Delta \mathrm{M}}\right) \ldots$...

- On page 2650, column 1, paragraph 2, the sentence "The more likely explanation for the lack of detectable levels of senescence and apoptosis after TRF2 deletion is that the hepatocytes remained in G0 in our experimental setting, whereas adenoviral infection induced cell cycle entry..." should now read "The more likely explanation for the lack of detectable levels of senescence after TRF2 deletion is that the hepatocytes remained in G0 in our experimental setting, whereas adenoviral infection induced cell cycle entry...".

\section{Material and methods}

On page 2652, column 2, paragraph 4, the sentence "Slides were incubated in the following primary antibodies diluted in blocking solution: y-H2AX (rabbit polyclonal, Upstate Biotecnology); phospso Histone H3 Ser10 (mouse monoclonal); anti-phosho p53 (Ser15) (Cell Signaling); cleaved Caspase 3 (Asp175) (Cell Signaling);..." should now read "Slides were incubated in the following primary antibodies diluted in blocking solution: $\gamma$-H2AX (rabbit polyclonal, Upstate Biotechnology); phospso Histone H3 Ser10 (mouse monoclonal); anti-phosho p53 (Ser15) (Cell Signaling);...".

The authors apologize for this regrettable error. This error does not alter the results or conclusions drawn from the experiments presented in the article.

doi: $10.1101 / \operatorname{gad} .349030 .121$ 


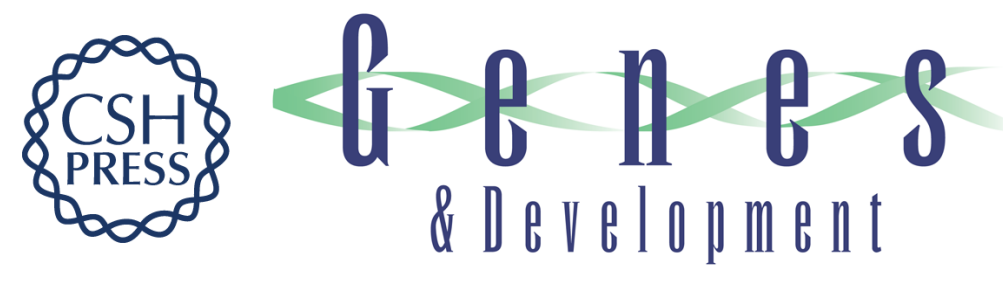

\section{Corrigendum: Hepatocytes with extensive telomere deprotection and fusion remain viable and regenerate liver mass through endoreduplication}

Eros Lazzerini Denchi, Giulia Celli and Titia de Lange

Genes Dev. 2021, 35:

Access the most recent version at doi:10.1101/gad.349030.121
Related Content Hepatocytes with extensive telomere deprotection and fusion remain viable and regenerate liver mass through endoreduplication
Eros Lazzerini Denchi, Giulia Celli and Titia de Lange
Genes Dev. October , 2006 20: 2648-2653

\section{License}
Email Alerting
Service
Receive free email alerts when new articles cite this article - sign up in the box at the top right corner of the article or click here.

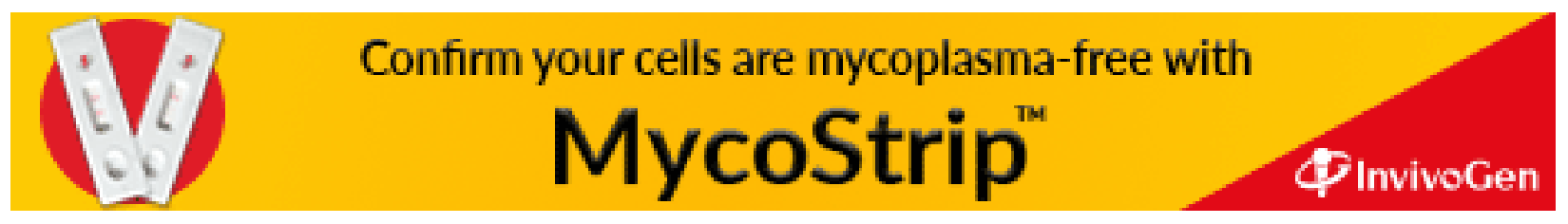

